\title{
APPLICATION OF EXCESS ACTIVATED SLUDGE AS WASTE SORBENT FOR DYES REMOVAL FROM THEIR AQUEOUS SOLUTIONS
}

\author{
WYKORZYSTANIE OSADU NADMIERNEGO JAKO SORBENTU \\ ODPADOWEGO DO USUWANIA BARWNIKÓW Z ROZTWORÓW WODNYCH
}

\begin{abstract}
Organic dyes are widely used in many industries (textiles, food, cosmetics, medicine and biology). These plants produce wastewater containing dyes. Even small amounts of dyes can cause a strong colour of wastewater. Therefore, it is very important to effectively remove residues of these pollutants from the wastewater, before discharging them into the environment. The sorption process is one of the methods used to remove dyes. However this method is often unprofitable economically in comparison with other dye removal processes, due to the high cost of commercial sorbents. Therefore, research is currently conducted in order to find waste materials that can be used as sorbents. The static sorption process of two dyes were carried out (Acid Red 18 and Acid Green 16) with the use of dried excess sludge. The activated sludge (excess) came from a municipal sewage treatment plant that purifies wastewater from carbon, nitrogen and phosphorus compounds. During the study the most favourable $\mathrm{pH}$ of the process and the contact time of the sorbent with the dyes were determined. It was observed that for both dyes the highest effectiveness of dye removal was obtained at $\mathrm{pH}=2$. The most favourable contact time was equal to 60 and 180 minutes for Acid Red 18 and Acid Green 16 respectively. In addition, in order to establish process parameters, a different models of sorption isotherm was examined. The studies showed that the sorption capacity (calculated based on Langmuir model) was much higher in the case of Acid Green 16 $\left(q_{m}=434.8 \mathrm{mg} / \mathrm{g}\right)$ than for Acid Red $18\left(q_{m}=109.9 \mathrm{mg} / \mathrm{g}\right)$. The experiments to evaluate the effect of $\mathrm{pH}$, contact time on the process effectiveness and to determine the sorption isotherm were conducted at $293.15 \mathrm{~K}$.
\end{abstract}

Keywords: dye, sorption process, waste sorbents, excess activated sludge, sorption isotherm

\section{Introduction}

Organic dyes are widely used many industries such as textile, food, dyeing, etc. [1-3]. Wastewater generated during production processes contains unused dyes. Even small concentrations of those compounds cause strong colour. Therefore, the wastewater containing dyes, when discharged into environment, contributes to the visual change of water colour. Moreover, the transparency of water into which untreated wastewater with dyes is introduced is lowered and therefore decreasing the ability of light penetration. That

\footnotetext{
${ }^{1}$ Faculty of Energy and Environmental Engineering, Silesian University of Technology in Gliwice, ul. S. Konarskiego 18, 44-100 Gliwice, Poland, phone +48 $32237 \quad 16$ 98, fax +48 $32237 \quad 1047$, email: rie4@polsl.pl

*Corresponding author: barbara.pieczykolan@polsl.pl
} 
causes disturbances in the photosynthesis process. Furthermore, many types of dyes can adversely affect the vital functions of both animal and plant organisms. They may cause allergic reactions and have muta- and cancerogenic effects $[4,5]$.

Azo dyes form a group of compounds that are often used in the textile industry, food industry, linen industry etc. They contain one or more azo groups with double bond between nitrogen atoms $-\mathrm{N}=\mathrm{N}-[6,7]$.

Therefore, it is important to effectively remove dyes from wastewater before introducing it into the environment. Many different purifying methods are used to treat this type of wastewater. Coagulation, chemical oxidation, electrochemical methods and sorption are applied to remove dyes from wastewater [1, 8-24]. The coagulation process, conducted with magnesium hydroxide enhanced by addition of kaolin, was used to remove two reactive dyes: reactive red $(\mathrm{X}-3 \mathrm{~B})$ and reactive yellow $(\mathrm{X}-\mathrm{R})$ [9]. The oxidation process conducted with ozone together with $\mathrm{Ca}(\mathrm{OH})_{2}$ was used for removal of Acid Red 18 [11]. Also Bessegato et al. used the ozonation process for mineralization of dye Acid Yellow 1 [10]. Moreover, these Authors used the photoelectrocatalytic oxidation to remove mentioned above dye. They applied $\mathrm{TiO}_{2}$ nanotubes electrode as photoanode in an annular bubble reactor with UV-B irradiation [10]. Many researchers use the Fenton reaction for degradation of the dyes. The classical heterogeneous Fenton method (for example to oxidize the azo methyl orange [14]) as well as different modifications of the Fenton process (for example bimetallic catalysts for decolourization of methyl orange and methylene blue removal in heterogeneous Fenton-like oxidation [15]) are frequently applied. Moreover, the physical adsorption process is used to remove the dyes from their aqueous solutions. For instance, Mirzaei et al. [1] modified the zoelite by hexadecyltrimethylammonium chloride and used it as sorbent for Acid Red 18 removal. Other example of sorption apllication for dye removal is research done by Zhang et al. [19]. They used the gemini surfactant-modified wheat bran for the removal of anionic azo dyes from aqueous solution. There are also examples of using biosorbents [20], clay [21], corncob [22], mango leaves biochar [23], sugarcane bagasse biochar [24] as adsorbents for dyes removal.

The sorption process is described by various isotherm models. The following two-parameter models: Freundlich, Langmuir, Temkin and Dubinin-Radushkevich are widely used. On their basis, different operational parameters are calculated, such as maximum adsorption capacity, sorption energy, heat of sorption etc.

The Langmuir isotherm is an empirical model describing monolayer sorption. It assumes that there are active sites on the adsorbent surface where only one molecule of adsorbate can be adsorbed. The adsorbed molecules do not move over the surface and form only a single layer called adsorption monolayer. Moreover, there is a finite number of definite localized sites [25-27]. This model is described by equation:

$$
q_{e}=\frac{q_{m} \cdot K_{L} \cdot C_{e}}{1+K_{L} \cdot C_{e}}
$$

where $K_{L}$ is a Langmuir constant related to the free energy of adsorption $\left[\mathrm{dm}^{3} / \mathrm{mg}\right]$ and $q_{m}$ is Langmuir constant related to the maximum adsorption capacity [mg/g].

The Freundlich isotherm describes an empirical model. It is used to define the sorption process on heterogenic surface [25-27]. Moreover, it assumes multilayer sorption where interactions not only between molecules and adsorbent surface but also between adsorbate molecules occur. It also assumes that the stronger binding sites are occupied first and that 
the binding strength decreases with the increasing degree of site occupation. It is represented by equation:

$$
q_{e}=K_{F} \cdot C_{e}^{1 / n}
$$

where $K_{F}$ is Freundlich constant which can roughly indicate the adsorption capacity $\left[\mathrm{mg}^{(1-1 / n)} \mathrm{dm}^{3(1 / n)} / \mathrm{g}\right]$ and $n$ is Freundlich constant which gives an indicator of the favourability of adsorption [-].

The Temkin isotherm equation assumes that the heat of adsorption of all the molecules in a layer decreases linearly with coverage due to adsorbent-adsorbate interactions and that the adsorption is characterised by an uniform distribution of the bonding energies, up to some maximum binding energy [28, 29]. It is usually used for heterogeneous surface energy systems (non-uniform distribution of sorption heat). Temkin model is described as follows:

$$
q_{e}=\frac{\mathrm{R} \cdot T}{b_{T}} \ln \left(K_{T} \cdot C_{e}\right)
$$

where $B_{T}=(\mathrm{R} \cdot T) / b_{T}$ is the Temkin constant related to heat of sorption $[\mathrm{J} / \mathrm{mol}], K_{T}$ is the Temkin constant $\left[\mathrm{dm}^{3} / \mathrm{g}\right], b_{T}$ is Temkin isotherm constant, $\mathrm{R}$ is the gas constant $(8.314 \mathrm{~J} / \mathrm{mol} \cdot \mathrm{K})$ and $T$ is the absolute temperature $[\mathrm{K}]$.

Dubinin-Radushkevich model is an empirical model initially formulated for the adsorption process following a pore filling mechanism. It is used to describe the sorption process that occurs onto both homogeneous and heterogeneous surfaces. The Authors of that model reported that the characteristic sorption curve was related to the porous structure of the sorbent. It is usually applied to differentiate between physical and chemical adsorption of metal ions [30,31]. The isotherm is described as follows:

$$
\begin{gathered}
q_{e}=q_{m} \cdot \exp \left(-K_{D R} \cdot \varepsilon^{2}\right) \\
\varepsilon=\mathrm{RT} \cdot \ln \left(1+\frac{1}{C_{e}}\right)
\end{gathered}
$$

where $q_{m}$ is adsorption capacity [mg/g], $K_{D R}$ is an activity coefficient constant related to sorption energy $\left[\mathrm{mol}^{2} / \mathrm{kJ}^{2}\right] ; \varepsilon$ is Polanyi potential. The $K_{D R}$ gives the mean free energy $(E[\mathrm{~kJ} / \mathrm{mol}])$ of sorption per molecule of the sorbate when it is transferred to the surface of the solid from infinity in the solution:

$$
E=\frac{1}{\sqrt{\left(2 \cdot K_{D R}\right)}}
$$

\section{Experimental}

The sorption of dyes on the surface of excess activated sludge (which was used as waste adsorbent) was examined at $293.15 \mathrm{~K}$. The sludge was collected from municipal wastewater treatment plant adapted to nitrogen compounds, organic matter and phosphorus removal. It was taken from the secondary settling tank. The sludge was first dewatered by evaporating the free water and then dried for $24 \mathrm{~h}$ in the $378.15 \mathrm{~K}$. Then it was ground and sieved through laboratory sieve.

Two types of acid dyes were used at the study: Acid Green 16 (Boruta-Kolor Company, Poland, C.I. 44025) further referred to as AG 16 and Acid Red 18 (Sigma-Aldrich Company, US, C.I. 16255) further referred to as AR 18. Working solutions 
of dyes were prepared by diluting $10 \mathrm{~g}$ of each dye in $1 \mathrm{dm}^{3}$ of distilled water. The sorption process was conducted in Erlenmeyer flasks of $300 \mathrm{~cm}^{3} .50 \mathrm{~cm}^{3}$ of dye solution (prepared on the basis of working solution) was introduced into the flask and the $\mathrm{pH}$ was adjusted to appropriate values (by using $10 \% \mathrm{NaOH}$ or $50 \% \mathrm{H}_{2} \mathrm{SO}_{4}$ ). Then $0.1 \mathrm{~g}$ of dried activated sludge with granulation $<0.49 \mathrm{~mm}$ was added into the flasks. The measurement of $\mathrm{pH}$ was made by potentiometric method using $\mathrm{pH}$-meter Elmetron $\mathrm{CX}-401$. The flasks with the mixture of dye solution and dried activated sludge were shaken for appropriate time with the laboratory shaker GFL 3005. Following the process, the sludge was separated from the solution and the residual concentrations of dyes were measured.

The dye concentrations were measured by colorimetric method based on the calibration curve: in the case of AG 16 at the wavelength $\lambda=631 \mathrm{~nm}$ and in the case of AR 18 - at $\lambda=506 \mathrm{~nm}$. The spectrophotometer spectroFlex 6100 (WTW) was used to measure the value of absorbance.

The experiment was divided into three parts. At the first series, the most favourable value of $\mathrm{pH}$ of sorption was established while the constant contact time $t$, constant concentration of dye $\left(C_{0}\right)$ and the same amount of sludge $\left(m_{s l}\right)$ were used. The second part of experiment was conducted in order to obtain the most favourable contact time (from 0 to 300 minutes). In the last series the tests were to determine the sorption isotherms for both dyes (at process parameters established earlier).

The most favourable value of $\mathrm{pH}$ and contact time was estimated based on the value of adsorbed amount of dye $q_{e}$ :

$$
q_{e}=\frac{\left(C_{0}-C_{e}\right)}{m_{s l}}
$$

where: $C_{0}$ - initial dye concentration in solution $\left[\mathrm{mg} / \mathrm{dm}^{3}\right], C_{e}$ - final dye concentration in solution $\left[\mathrm{mg} / \mathrm{dm}^{3}\right], m_{s l}$ - weight of dried excess sludge $\left[\mathrm{g} / \mathrm{dm}^{3}\right]$.

Linear forms of isotherm models are described by equations (8)-(13).

Freundlich model:

$$
\log q_{e}=\log K_{F} \cdot \frac{1}{n} \log C_{e}
$$

Langmuir model:

$$
\begin{gathered}
\frac{C_{e}}{q_{e}}=\frac{C_{e}}{q_{m}}+\frac{1}{K_{L} \cdot q_{m}} \\
\frac{1}{q_{e}}=\frac{1}{K_{L} \cdot q_{m}} \cdot \frac{1}{C_{e}}+\frac{1}{q_{m}} \\
q_{e}=q_{m}-\frac{1}{K_{L}} \cdot \frac{q_{e}}{C_{e}}
\end{gathered}
$$

Temkin model:

$$
q_{e}=\frac{\mathrm{R} \cdot T}{b_{T}} \ln C_{e}+\frac{\mathrm{R} \cdot T}{b_{T}} \ln K_{T}
$$

Dubinin-Radushkevich model:

$$
\ln q_{e}=\ln q_{m}-K_{D R} \cdot \varepsilon^{2}
$$

In the third stage of the study, four two-parameter isotherm models were used in order to describe sorption process: Freundlich, Langmuir, Dubinin-Radushkevich and Temkin. 
In order to determine the parameters of each model the estimation was conducted based on the linear forms of isotherm equations (eqs. (8)-(13)). In the case of Langmuir model three types of linear equation were used (eqs. (9)-(11)). The correlation coefficient $R^{2}$ was determined for each linear equation. And the Langmuir isotherm parameters were determined based on the equation, in which the highest $R^{2}$ was obtained.

\section{Results and discussion}

\section{Stage I: effect of $\mathbf{p H}$}

In the first stage of the experiments, the selection of the most favourable $\mathrm{pH}$ value was made from the following values: $2,4,6,8$ and 10. During that series the initial concentration of dye in the solution was equal to $700 \mathrm{mg} / \mathrm{dm}^{3}$, contact time was 60 minutes and the amount of sludge was $2 \mathrm{~g} / \mathrm{dm}^{3}$. The studies showed that the highest effectiveness of the sorption process was observed at $\mathrm{pH}=2$ for both dyes (Fig. 1a and 1b). At those conditions the removal efficiency was $56.8 \%\left(C_{e}=302 \mathrm{mg} / \mathrm{dm}^{3}\right)$ and $25.9 \%$ $\left(C_{e}=519 \mathrm{mg} / \mathrm{dm}^{3}\right)$ for AG 16 and AR 18 respectively. When the $\mathrm{pH} 4$ and higher values were used the efficacy decreased to 0 and the dye concentrations in solutions were $700 \mathrm{mg} / \mathrm{dm}^{3}$ for both dyes. This may indicate that the surface charge of dried activated sludge is negative. Moreover, both dyes when subject to hydrolysis process get a negative charge (they become anions). Therefore, only the formation of the positive charge on the surface of the sludge (by strong acidification of the dye solution and the phenomenon of protonation of the surface) allowed for the interaction between molecules of dyes and adsorbent.

a)

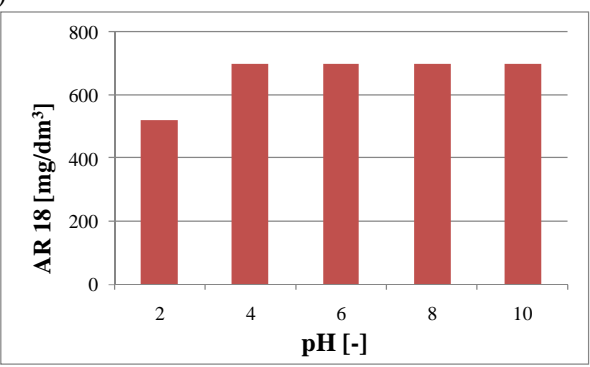

b)

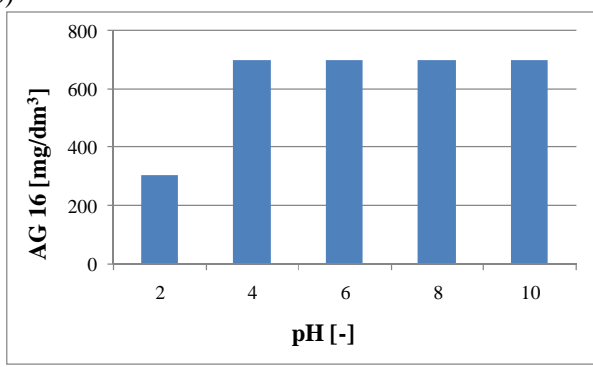

Fig. 1. The effect of $\mathrm{pH}$ on efficiency of sorption process at $t=60 \mathrm{~min}, C_{0}=700 \mathrm{mg} / \mathrm{dm}^{3}, m_{s l}=2 \mathrm{~g} / \mathrm{dm}^{3}$ : a) dye AR 18, b) dye AG 16

\section{Stage II: contact time}

Various contact times (from 5 to 300 minutes) were used in the second stage of the study. The other process parameters were constant and as follows: $\mathrm{pH}=2$, initial concentration of dye $C_{0}=700 \mathrm{mg} / \mathrm{dm}^{3}$ and amount of sorbent $m_{s l}=2 \mathrm{~g} / \mathrm{dm}^{3}$. Generally, extending the contact time contributed to the increasing of the efficiency of the sorption process and the adsorbed load expressed as $q_{t}$ also increased (Fig. 2a and 2b). In the case of AR 18 the most significant increase of $q_{t}$ value was observed in the first 30 minutes of reaction - $q_{t}$ was $77.9 \mathrm{mg} / \mathrm{g}$ (Fig. 2a). Extending the contact time to 60 minutes contributed only to a slight increase of efficacy of the process (the value of adsorbed load was only 
$8.8 \mathrm{mg} / \mathrm{g}$ higher than after 30 minutes). Further extending reaction time up to 300 minutes did not improve the effectiveness - the $q_{t}$ maintained the steady level.

a)

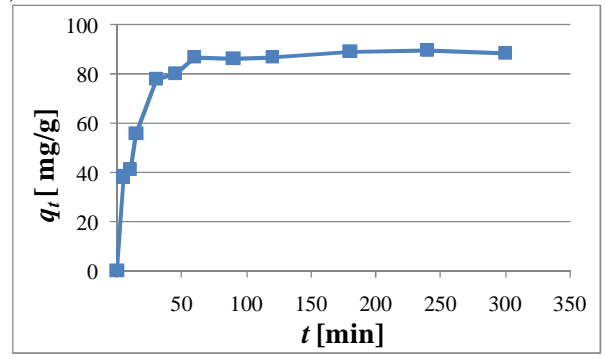

b)

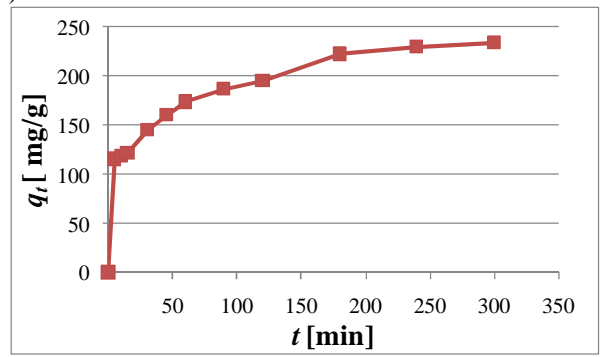

Fig. 2. The effect of contact time on efficiency of sorption process at $\mathrm{pH}=2.0, C_{0}=700 \mathrm{mg} / \mathrm{dm}^{3}$, $m_{s l}=2 \mathrm{~g} / \mathrm{dm}^{3}:$ a) AR 18, b) AG 16

In the case of AG 16 it was observed that sorption proceeded the fastest during the first 5 minutes (Fig. 2b). The adsorbed amount of dye then increased up to $115.4 \mathrm{mg} / \mathrm{g}$. After that contact time, further increase of effectiveness was observed (at $t=180 \mathrm{~min}$ the $q_{t}=222.3 \mathrm{mg} / \mathrm{g}$ ), however it was much slower than in the mentioned first period. Extending the contact time to 240 minutes and 300 minutes only slightly increased the efficiency of the process - $q_{t}$ was equal to 229.5 and $234.1 \mathrm{mg} / \mathrm{g}$ respectively. It can be concluded that the required contact time was 180 minutes in the case of AG 16.

Based on the results obtained at that part of the studies, the most favourable contact times were 60 and 180 minutes for dye AR 18 and AG 16 respectively.

\section{Stage III: sorption isotherm}

The last stage of the study included the experiments with varying dye mass to sorbent mass ratio to determine the sorption isotherm.

a)

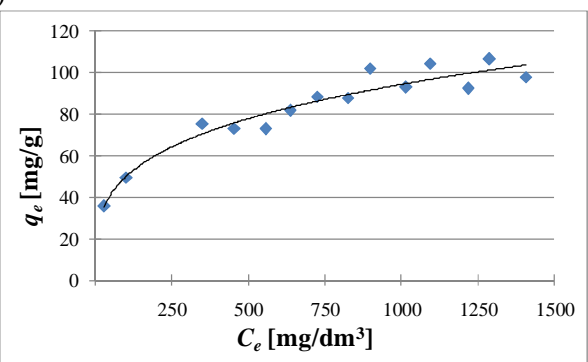

b)

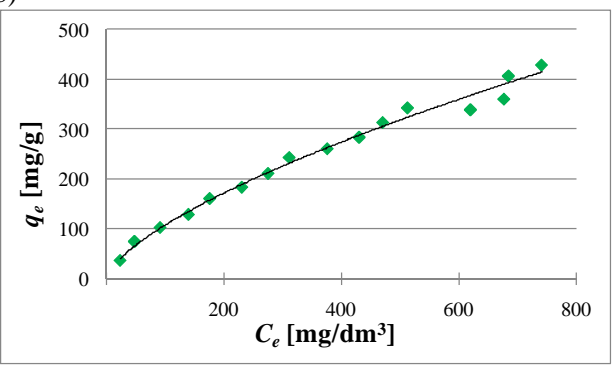

Fig. 3. Sorption isotherm at $\mathrm{pH}=2.0, m_{s l}=2 \mathrm{~g} / \mathrm{dm}^{3}$ : a) AR 18 at $t=60 \mathrm{~min}$, b) AG 16 at $t=180 \mathrm{~min}$

The curves of sorption isotherms for both dyes are showed in the Figures $3 \mathrm{a}$ and $3 \mathrm{~b}$. The above curves when compared to the classification of isotherm curves by Brunauer et al. [32], where the type of adsorption may be determined on the basis of the shape of the 
obtained curve, suggest that in the case of AR 18 monolayer sorption occurred whereas for AG 16 - multilayer sorption occurred. It was also observed that much higher amounts of dye AG 16 were adsorbed by dried activated sludge in comparison with AR 18. This could be due to the fact that in the case of AG 16 multilayer sorption occurred, whereas in the case of AR 18 - monolayer sorption. When the multilayer sorption takes place, the molecules of dyes are adsorbed not only on the nearest layer of the surface. In that case on the first monolayer of molecules other molecules are adsorbed and other layers are formed.

Moreover, based on the study results, the curves of linear forms of each model were made. The graphs: $\log \left(q_{e}\right)$ vs. $\log \left(C_{e}\right)$ and $\ln \left(q_{e}\right)$ vs. $\varepsilon^{2}$ and $q_{e}$ vs. $\ln \left(C_{e}\right)$ were plotted in the case of Freundlich, Dubinin-Raduskevich and Temkin respectively (Figs. 4-6). For Langmuir model following curves were plotted: $C_{e} / q_{e}$ vs. $C_{e} ; 1 / q_{e}$ vs. $\left(1 / C_{e}\right)$ and $q_{e}$ vs. $\left(q_{e} / C_{e}\right)$ - Figures 7 and 8 . Based on those graphs, the values of parameters were determined for all isotherm models. In the case of Langmuir isotherm, the values of $q_{m}$ and $K_{L}$ were calculated from the linear equation for which the highest value of $R^{2}$ was obtained. For dye AR 18, the highest $R^{2}$ was observed for the first linear form described by equation (9). However, in the case of AG 16 - the maximum $R^{2}$ value was obtained when the linear form was described by equation (10).

\section{Langmuir isotherm and Freundlich isotherm}

The experiments showed that in the case of dye AR 18, higher value of correlation coefficient $R^{2}$ was observed for linear form of Langmuir isotherm model in comparison with the Freundlich model (Table 1). As it is known, Langmuir model describes monolayer sorption. In accordance with previous considerations, the shape of isotherm curve $q_{e}=f\left(C_{e}\right)$ also testified that a monolayer sorption could occur - the 1st type of isotherm by Brunauer division. However, the analysis of the sorption process results for the dye AG 16 showed that a higher $R^{2}$ value was obtained for the linear form of the Freundlich isotherm described by the formula (8) (Fig. 4 and Table 1). The Freundlich model describes multilayer sorption. Also in this case, the conclusion regarding the occurrence of the multilayer sorption, based on the results of the linear estimation coincides with the conclusion drawn on the basis of the shape of the curve $q_{e}=f\left(C_{e}\right)$.

a)

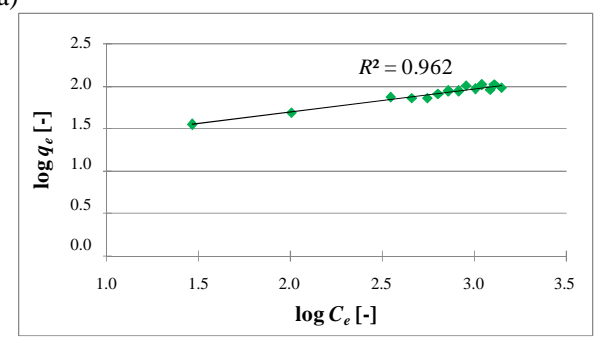

b)

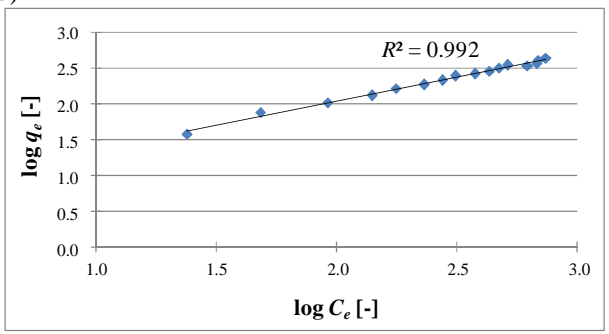

Fig. 4. Linear form of Freundlich sorption model at $\mathrm{pH}=2.0, m_{s l}=2 \mathrm{~g} / \mathrm{dm}^{3}$ : a) AR 18 at $t=60 \mathrm{~min}$, b) AG 16 at $t=180 \mathrm{~min}$

In addition, based on the linear equations of the Langmuir isotherm, the sorption capacity of the tested sludge was determined for both dyes. It was observed that in the case of dye AG 16, the value of $q_{m}$ was approximately four times greater than in the case of dye 
AR 18. The parameter $q_{m}$ was equal to $434.8 \mathrm{mg} / \mathrm{g}$ and $109.9 \mathrm{mg} / \mathrm{g}$ for AG 16 and AR 18, respectively.

\section{Temkin isotherm}

Based on the results of the tests related to the determination of the sorption isotherm, the Temkin model parameters was also established based on the linear form of model equation (Table 1 and Fig. 5). It was observed that a higher value of $R^{2}$ correlation coefficient was obtained for the dye AG 16 (0.948) than for the dye AR 18 (0.910). However, it should be noted that the $R^{2}$ values were very similar for both dyes. In addition, the parameter $B_{T}$, defining the heat of sorption, was determined. Studies have also shown that a higher value of sorption heat was observed for the adsorption of AR 18 (17.9 J/mol) in comparison with AG $16(154 \mathrm{~J} / \mathrm{mol})$. It was almost a hundred times greater for AR 18 then for AG 16.

a)

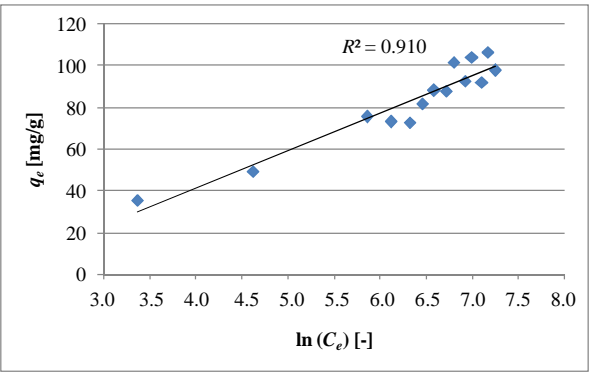

b)

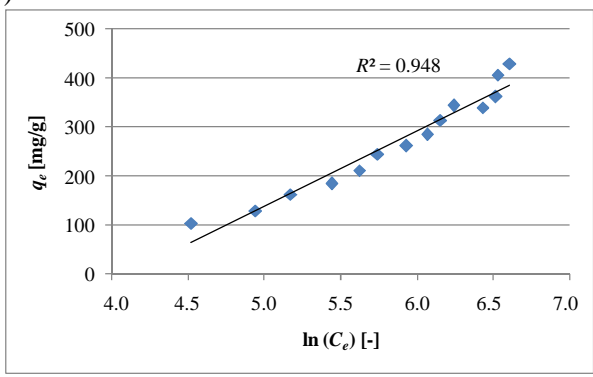

Fig. 5. Linear form of Temkin sorption model at $\mathrm{pH}=2.0, m_{s l}=2 \mathrm{~g} / \mathrm{dm}^{3}:$ a) AR 18 at $t=60 \mathrm{~min}$, b) AG 16 at $t=180 \mathrm{~min}$

\section{Dubinin-Radushkevich isotherm}

The parameters of Dubinin-Radushkevich model were established based on the linear form of isotherm equation. In that case, higher correlation coefficient value was obtained for adsorption of AG 16 (0.723) than for AR 18 (0.641) - Table 1 and Figure 6. The energy of sorption for both dyes was calculated based on the value of $K_{D R}$ constant. The higher energy was observed in the case of AR 18 adsorption on the surface of dried excess sludge $0.061 \mathrm{~kJ} / \mathrm{mol}$ compared to AG $16-0.016 \mathrm{~kJ} / \mathrm{mol}$. As the value of sorption energy is known, the type of adsorption process may be established - if the physical or chemical sorption occurs. The chemical sorption takes place when the value of sorption energy is higher than $16 \mathrm{~kJ} / \mathrm{mol}$. Physical adsorption takes place, when the value of this energy is lower than $8 \mathrm{~kJ} / \mathrm{mol}$. however, when the value of $E$ is in range $8-16 \mathrm{~kJ} / \mathrm{mol}$ the ion exchange occurs [33]. In the study the physical sorption occurred in the case of dye both dyes.

Moreover, based on the Dubinin-Radushkevich model the sorption capacity $q_{m}$ was calculated. Similar to the case of the Langmuir model, much higher value of that parameter was obtained for AG 16 (85.6 mg/g) in comparison with AR $18(312.8 \mathrm{mg} / \mathrm{g})$. It may be also observed that, the values established according to Dubin-Radushkevich model were similar to values calculated from Langmuir model. It may indicate that the multilayer sorption occurred in the case of dye AG 16, therefore higher amount of dye could be adsorbed per unit weight of the sorbent. 
a)

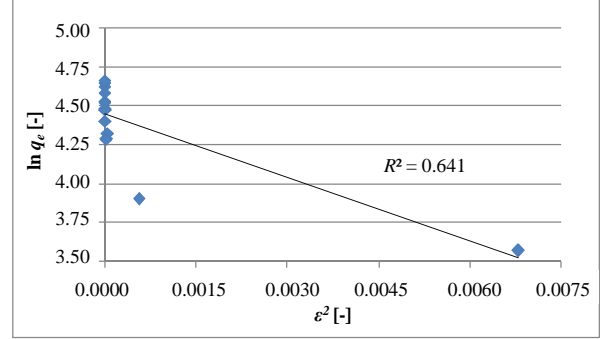

b)

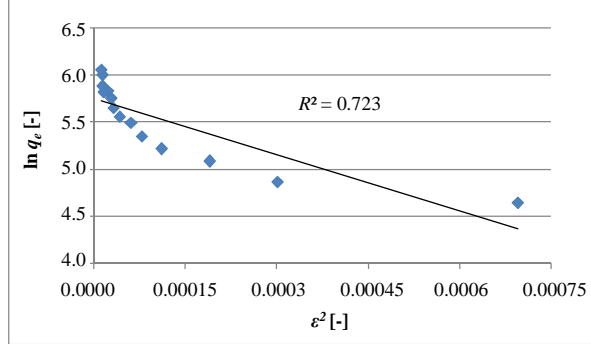

Fig. 6. Linear form of Dubinin-Radushkevich sorption model at $\mathrm{pH}=2.0, m_{s l}=2 \mathrm{~g} / \mathrm{dm}^{3}$ : a) AR 18 at $t=60 \mathrm{~min}, \mathrm{~b})$ AG 16 at $t=180 \mathrm{~min}$

a)

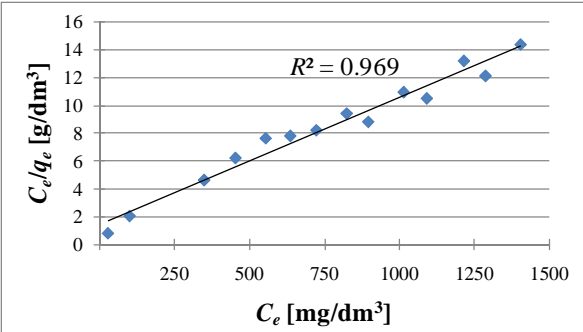

b)

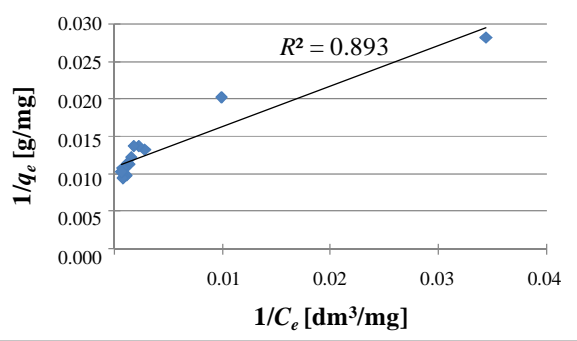

c)

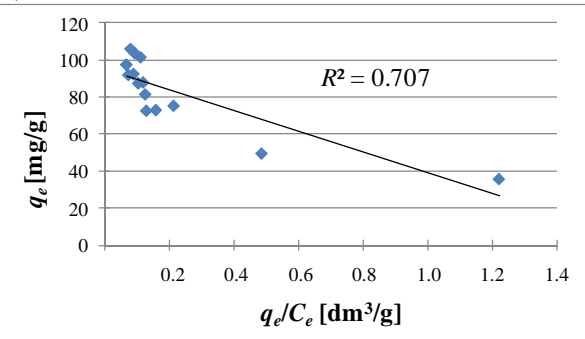

Fig. 7. Linear forms of Langmuir sorption model of $\mathrm{AR} 18$ at $\mathrm{pH}=2.0, m_{s l}=2 \mathrm{~g} / \mathrm{dm}^{3}$ : a) form 1 (according to eq. (9)), b) form 1 (according to eq. (10)), c) form 1 (according to eq. (11))

Values of parameters of two-parameter models for AR 18 and AG 16

Table 1

\begin{tabular}{|c|c|c|c|c|}
\hline Isotherm model & Dye & Parameter & Unit & Value \\
\hline \multirow{6}{*}{ Freundlich } & \multirow{3}{*}{ AR 18} & $1 / n$ & {$[-]$} & 0.277 \\
\hline & & $K_{F}$ & {$\left[\mathrm{mg}^{(1-1 / n)} \mathrm{dm}^{3(1 / n)} / \mathrm{g}\right]$} & 13.9 \\
\hline & & $R^{2}$ & {$[-]$} & 0.962 \\
\hline & \multirow{3}{*}{ AG 16} & $1 / n$ & {$[-]$} & 0.668 \\
\hline & & $K_{F}$ & {$\left[\mathrm{mg}^{(1-1 / n)} \mathrm{dm}^{3(1 / n)} / \mathrm{g}\right]$} & 5.03 \\
\hline & & $R^{2}$ & {$[-]$} & 0.992 \\
\hline \multirow{6}{*}{ Langmuir } & \multirow{3}{*}{ AR 18} & $K_{L}$ & {$\left[\mathrm{dm}^{3} / \mathrm{mg}\right]$} & 0.006 \\
\hline & & $q_{m}$ & {$[\mathrm{mg} / \mathrm{g}]$} & 109.9 \\
\hline & & $R^{2}$ & {$[-]$} & 0.969 \\
\hline & \multirow{3}{*}{ AG 16} & $K_{L}$ & {$\left[\mathrm{dm}^{3} / \mathrm{mg}\right]$} & 0.004 \\
\hline & & $q_{m}$ & {$[\mathrm{mg} / \mathrm{g}]$} & 434.8 \\
\hline & & $R^{2}$ & {$[-]$} & 0.989 \\
\hline
\end{tabular}




\begin{tabular}{|c|c|c|c|c|}
\hline Isotherm model & Dye & Parameter & Unit & Value \\
\hline \multirow{6}{*}{ Temkin } & \multirow{3}{*}{ AR 18} & $B_{T}$ & {$[\mathrm{~J} / \mathrm{mol}]$} & 17.9 \\
\hline & & $K_{T}$ & {$\left[\mathrm{dm}^{3} / \mathrm{g}\right]$} & 0.183 \\
\hline & & $R^{2}$ & {$[-]$} & 0.910 \\
\hline & \multirow{3}{*}{ AG 16} & $B_{T}$ & {$[\mathrm{~J} / \mathrm{mol}]$} & 154 \\
\hline & & $K_{T}$ & {$\left[\mathrm{dm}^{3} / \mathrm{g}\right]$} & 0.017 \\
\hline & & $R^{2}$ & {$[-]$} & 0.948 \\
\hline \multirow{8}{*}{$\begin{array}{c}\text { Dubinin- } \\
\text { Radushkevich }\end{array}$} & \multirow{4}{*}{ AR 18} & $K_{D R}$ & {$\left[\mathrm{~mol}^{2} / \mathrm{kJ}^{2}\right]$} & 136 \\
\hline & & $q_{m}$ & {$[\mathrm{mg} / \mathrm{g}]$} & 85.6 \\
\hline & & $E$ & {$[\mathrm{~kJ} / \mathrm{mol}]$} & 0.061 \\
\hline & & $R^{2}$ & {$[-]$} & 0.641 \\
\hline & \multirow{4}{*}{ AG 16} & $K_{D R}$ & {$\left[\mathrm{~mol}^{2} / \mathrm{kJ}^{2}\right]$} & 1977 \\
\hline & & $q_{m}$ & {$[\mathrm{mg} / \mathrm{g}]$} & 312.8 \\
\hline & & $E$ & {$[\mathrm{~kJ} / \mathrm{mol}]$} & 0.016 \\
\hline & & $R^{2}$ & {$[-]$} & 0.723 \\
\hline
\end{tabular}

a)

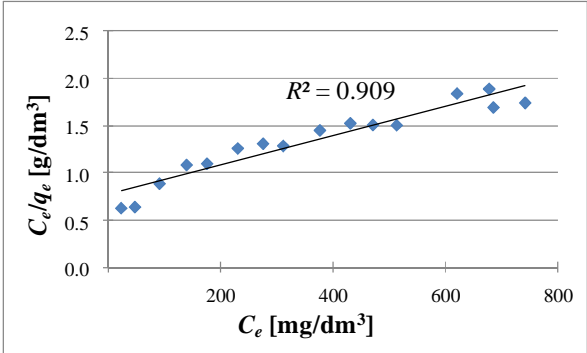

b)

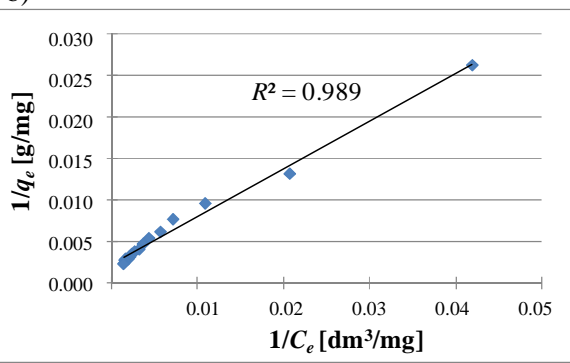

c)

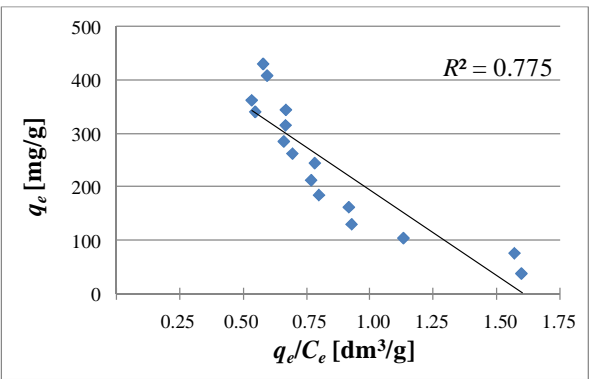

Fig. 8. Linear forms of Langmuir sorption model of dye AG 16 at $\mathrm{pH}=2.0, m_{s l}=2 \mathrm{~g} / \mathrm{dm}^{3}$ : a) form 1 (according to eq. (9)), b) form 2 (according to eq. (10)), c) form 3 (according to eq. (11))

\section{Conclusions}

- The most favourable value of $\mathrm{pH}$ for both dyes was equal to 2; application of lower or higher value of $\mathrm{pH}$ contributed to decrease the efficiency; it may be assumed that the surface charge of the sludge is negative as well as the dissociated dye molecules, therefore the application of $\mathrm{pH}=2$ caused the change of charge surface into positive (due to the protonation of surface phenomena) and allowed the mutual attraction of adsorbate and adsorbent.

- The most favourable contact time was equal to 60 and 180 minutes for AR 18 and AG 16 respectively when the experiments were conducted at conditions: $\mathrm{pH}=2$, initial 
concentration of dye $C_{0}=700 \mathrm{mg} / \mathrm{dm}^{3}$, temperature $293.15 \mathrm{~K}$ and mass of dye $m_{s l}=2 \mathrm{~g} / \mathrm{dm}^{3}$.

- The sorption isotherm studies showed that in the case of AR 18 the monolayer sorption occurred (the 1st type of isotherm by Brunauer classification), and in the case AG 16 multilayer (the 2nd type of isotherm by Brunauer classification).

- It was established that much higher value of sorption capacity was obtained for AG 16 then AR 18; $q_{m}$ calculated based on Langmuir model was equal to $434.8 \mathrm{mg} / \mathrm{g}$ and $109.9 \mathrm{mg} / \mathrm{g}$ for AG 16 and AR 18 respectively; similar, but lower, values of $q_{m}$ was obtained when this parameter was established according to Dubinin-Radushkevich sorption model (for AR $18 q_{m}=85.6 \mathrm{mg} / \mathrm{g}$ and for AG $16 q_{m}=312.8 \mathrm{mg} / \mathrm{g}$ ).

- Based on the Dubinin-Radushkevich model the mean free energy of sorption was determined; it can be observed that physical process occurred for both dyes (the value of $E$ was much lower than $8 \mathrm{~kJ} / \mathrm{mol}$ ).

\section{Acknowledgements}

This work was supported by Ministry of Science and Higher Education Republic of Poland within statutory funds.

\section{References}

[1] Mirzaei N, Ghaffari MR, Sharafi K, Velayati A, Hoseindoost G, Rezaei S, et al. J Environ Chem Eng. 2017;5:3151-60. DOI: 10.1016/j.jece.2017.06.008.

[2] Saharan VK, Badve MP, Pandit AB. Chem Eng J. 2011;178(0):100-7. DOI: 10.1016/j.cej.2011.10.018.

[3] Kuriechena SK, Murugesan S, Raja SP, Maruthamuthu P. Chem Eng J. 2011;174(2-3):530-8. DOI:10.1016/j.cej.2011.09.024.

[4] Patel YN, Patel MP. J Environ Chem Eng. 2013;1:1368-74. DOI: 10.1016/j.jece.2013.09.024.

[5] Shokoohi R, Vatanpoor V, Zarrabi M, Vatani A. E-J Chem. 2010;7:65-72. https://www.hindawi.com/journals/jchem/2010/958073.

[6] Malakootian M, Moridi A. Process Safety Environ Prot. 2017;111:138-47. DOI: 10.1016/j.psep.2017.06.008.

[7] Parsa JB, Golmirzaei M, Abbasi M. J Industrial Eng Chem. 2014;20(2):689-94. DOI: 10.1016/j.jiec.2013.05.034.

[8] Liang C-Z, Sun S-P, Li F-Y, Ong Y-K, Chung T-S. J Membr Sci. 2014;469:306-15. DOI: 10.1016/j.memsci.2014.06.057.

[9] Li HY, Liu SY, Zhao JH, Feng N. Colloids Surfaces A: Physicochem Eng Aspects. 2016; 494:222-7. DOI: 10.1016/j.colsurfa.2016.01.048.

[10] Bessegato GG, Cardoso JC, Ferreira da Silva B, Zanoni MVB. Appl Catal B: Environ. 2016;180:161-8. DOI: 10.1016/j.apcatb.2015.06.013.

[11] Quan X, Luo D, Wu J, Li R, Cheng W, Ge S. J Environ Chem Eng. 2017;5:283-91. DOI: 10.1016/j.jece.2016.12.007.

[12] Yuan R, Ramjaun SN, Wang Z, Liu J. Chem Eng J. 2012;192:171-78. DOI: 10.1016/j.cej.2012.03.080.

[13] Leite de Oliveira R, Anderson MA, Umbuzeiro GA, Zocoloa GJ, Zanoni MVB. J Hazard Mater. 2012;205-206:1-9. DOI:10.1016/j.jhazmat.2011.10.060.

[14] Quadrado RFN, Fajardo AR. Carbohydr Polym. 2017;177:443-50. DOI: 10.1016/j.carbpol.2017.08.083.

[15] Song H, Chen C, Zhang H, Huang J. J Environ Chem Eng. 2016;4:460-7. DOI: 10.1016/j.jece.2015.12.003.

[16] Khan ZUH, Khan A, Chen Y, Khan AU, Shah NS, Muhammad N, et al. J Alloys Compounds. 2017;725:869-76. DOI: 10.1016/j.jallcom.2017.07.222.

[17] Babu J, Murthy ZVP. Separation Purif Technol. 2017;183:66-72. DOI: 10.1016/j.seppur.2017.04.002.

[18] Liu M, Chen Q, Lu K, Huang W, Lü Z, Zhou C, et al. Separation Purif Technol. 2017;173:135-43. DOI: 10.1016/j.seppur.2016.09.023.

[19] Zhang Y, Huang G, An C, Xin X, Liuc X, Ramand M, et al. Sci Total Environ. 2017; 595:723-32. DOI: 10.1016/j.scitotenv.2017.04.031. 
[20] Liu J, Chen F, Li C, Lu L, Hu C, Wei Y, et al. J Clean Prod. 2019;208:552-62. DOI: 10.1016/j.jclepro.2018.10.136.

[21] Kausar A, Iqbal M, Javed A, Aftab K, Nazli Z-i-H, Bhatti HN, et al. J Mol Liq. 2018;256:395-407. DOI: 10.1016/j.molliq.2018.02.034.

[22] Tomczak E, Blus M. Ecol Chem Eng S. 2016;23(1):175-85. DOI: 10.1515/eces-2016-0012.

[23] Vyavahare GD, Jadhav P, Jadhav J, Patil R, Aware C, Patil D, et al. J Clean Prod. 2019;207:296-305. DOI: 10.1016/j.jclepro.2018.09.193.

[24] Vyavahare GD, Gurav RG, Jadhav PP, Patil RR, Chetan B. Aware CB, et al. Chemosphere. 2018;194:306-15. DOI: 10.1016/j.chemosphere.2017.11.180.

[25] Basar CA. J Hazard Mater B. 2006;135:232-41. DOI: 10.1016/j.jhazmat.2005.11.055.

[26] Allen SJ, Gan Q, Matthews R, Johnson PA. Biores Technol. 2003;88:143-52. DOI: 10.1016/S0048-9697(03)00133-5.

[27] Crini G, Badot P-M. Sorption Processes and Pollution. Conventional and Non-conventional Sorbents for Pollutant Removal from Wastewaters. Presses Universitaires de Franche-Comte. Universite de Franche-Comte. 2010. ISBN: 9782848673042.

[28] Temkin, MI, Pyzhev V. Acta Physicochim URSS. 1940;12(3):217-22.

[29] Hadi M, Samarghandi MR, McKay G. Chem Eng J. 2010;160:408-16. DOI: 10.1016/j.cej.2010.03.016.

[30] Dubinin MM, Radushkevich LV. Dokl Akad Nauk SSSR. 1947;55:327-9.

[31] Dubinin MM. Chem Rev. 1960;60(2):235-41. https://www.app-one.com.cn/UpFile/20130618120102.pdf.

[32] Brunauer S, Deming LS, Deming WE, Teller EJ. J Am Chem Soc. 1940;62(7):1723-32. https://pubs.acs.org/doi/pdf/10.1021/ja01864a025

[33] Amrhar O, Nassali H, Elyoubi MS. J Chem Pharm Res. 2015;7(9);892-903. http://www.jocpr.com/archive/jocpr-volume-7-issue-9-year-2015.html. 